\title{
Effects of Hepatitis C Virus Elimination by Direct-Acting Antiviral Agents on the Occurrence of Oral Lichen Planus and Periodontal Pathogen Load: A Preliminary Report
}

\author{
Yumiko Nagao $\mathbb{D}^{1,2,3}$ and Masahide Tsuji ${ }^{3}$ \\ ${ }^{1}$ Department of Public Health, Graduate School of Medicine, Juntendo University, Tokyo 113-8421, Japan \\ ${ }^{2}$ Liver Center, Saga University Hospital, Nabeshima, Saga 849-8501, Japan \\ ${ }^{3}$ Tsuji Dental \& Oral Surgery Clinic, Shiragane-machi, Omuta, Fukuoka 836-0052, Japan
}

Correspondence should be addressed to Yumiko Nagao; y.nagao.qd@juntendo.ac.jp

Received 24 August 2021; Revised 21 September 2021; Accepted 25 October 2021; Published 11 November 2021

Academic Editor: Gaetano Isola

Copyright (c) 2021 Yumiko Nagao and Masahide Tsuji. This is an open access article distributed under the Creative Commons Attribution License, which permits unrestricted use, distribution, and reproduction in any medium, provided the original work is properly cited.

\begin{abstract}
Objective. The association between hepatitis $\mathrm{C}$ virus (HCV) and oral lichen planus (OLP) is well known, but the association with periodontal disease has been reported less often. The purpose of this study was to investigate the effects of periodontal bacteria and OLP lesions before and after HCV elimination. Subjects and Methods. The subjects were four OLP patients (mean age 72.5 years) with HCV infection. Six types of periodontal bacteria (Aggregatibacter actinomycetemcomitans, Prevotella intermedia, Porphyromonas gingivalis, Tannerella forsythia, Treponema denticola, and Fusobacterium nucleatum) were quantified in saliva, and changes in OLP were examined before and after elimination of HCV by antiviral therapy. Biochemical blood tests also were performed. Results. The total number of periodontal bacteria, the numbers of $P$. gingivalis, T. forsythia, T. denticola, and $F$. nucleatum, and the risk of presenting with the red-complex bacteria (P. gingivalis, T. forsythia, and T.denticola), leading to periodontal disease progression, decreased after HCV elimination. OLP disappeared in three of the four patients and decreased in the other after sustained virological responses (SVRs). Conclusion. HCV elimination not only improved OLP lesions but also reduced the number of periodontal pathogens and the amount of red-complex periodontal pathogens.
\end{abstract}

\section{Introduction}

Hepatitis C virus (HCV) infection affects approximately 71 million people worldwide and is a leading cause of chronic liver disease and liver cancer deaths $[1,2]$. In Japan, liver cancer accounts for about 30,000 deaths per year, $80 \%$ of which are caused by hepatitis B virus (HBV) and HCV [3]. $\mathrm{HCV}$-infected patients in Japan are generally older than in other countries and are characterized by a high proportion of patients with complications such as cirrhosis and liver cancer $[4,5]$. Since 2014, the treatment of chronic hepatitis C has been revolutionized by the advent of oral direct-acting antiviral agents (DAAs) [6]. Because DAA treatment has enabled the elimination of HCV, in May 2016, the World Health Organization (WHO) aimed to eliminate viral hepatitis as a major public health threat by $2030[7,8]$.
$\mathrm{HCV}$ infection is known to cause manifestations other than liver disease [9]. Oral lichen planus (OLP), which is recognized as an oral potentially malignant disorder (OPMD), is one of these extrahepatic manifestations $[10,11]$. In addition to glucocorticoids and immunosuppressive drugs (cyclosporine), the efficacy of tacrolimus, clobetasol [12], pimecrolimus [13], and glycyrrhizin [14] has been reported for the treatment of OLP. We have reported that OLP can be cured when HCV is eliminated by antiviral treatments, such as with interferon (IFN) [15] and DAA [16-19]. Achieving a sustained virological response (SVR) has been shown to reduce not only liver cancer deaths and liver disease-related deaths but also extrahepatic mortality [20, 21].

Periodontal disease is associated with systemic health [22] and with liver disease, particularly nonalcoholic steatohepatitis (NASH) [23]. As a new biomarker involved in 
periodontal inflammation, galectin-3 has recently been shown to have the potential to discriminate between periodontitis and periodontal health [24]. We reported previously that there is an association between the severity of periodontal disease and the progression of viral liver disease [25] and that the so-called red-complex bacterial species (Porphyromonas gingivalis, Tannerella forsythia, and Treponema denticola) which are associated with severe periodontal disease are also associated with liver cirrhosis [26]. However, the changes in periodontal pathogens with and without HCV elimination have not been reported. Here, we report, as a preliminary study, the changes in periodontal species after HCV elimination by antiviral therapy in four OLP patients. The aim of this study was to investigate the effect of periodontal bacteria and OLP lesions before and after HCV elimination.

\section{Subjects and Methods}

2.1. Patients. The subjects were those who met the following eligibility criteria: (i) diagnosed with chronic hepatitis $\mathrm{C}$ and oral lichen planus; (ii) achieved SVR by DAA treatment; (iii) underwent saliva collection and oral mucosal examination at least twice before and after DAA treatment; (iv) positive for HCV antibody and HCV RNA, but negative for hepatitis B surface antigen (HBsAg); (v) any gender; and (vi) obtained written consent for this study. Exclusion criteria are as follows: (i) subjects who had not given consent; (ii) subjects who had not received DAA treatment; (iii) subjects who had not achieved SVR with DAA treatment; (iv) complications of other liver diseases (chronic hepatitis B, autoimmune hepatitis, primary biliary cirrhosis, primary sclerosing cholangitis, Wilson's disease, etc.); and (v) the presence of hepatocellular carcinoma (HCC) (except for patients with no recurrence for more than one year after treatment for HCC).

The subjects were four OLP patients (two males and two females) with HCV infection who consented to oral examinations and saliva collection before DAA treatment and after SVR. The ages of the subjects ranged from 65 to 77 years, with a mean of $72.5 \pm 5.4$ years. The background information of the subjects is shown in Table 1. The four patients visited Saga University, Kurume University, or Tsuji Dental and Oral Surgery Clinic between May 2013 and June 2015. The oral and liver diseases of each patient were diagnosed by an oral surgeon and a hepatologist. Three of the four patients received DAA treatment with daclatasvir (DCV; NS5A inhibitor) and asunaprevir (ASV; NS3 protease inhibitor), and the other received DAA treatment with sofosbuvir (SOF; NS5B inhibitor) and ribavirin (RBV), all of which resulted in SVR.

2.2. Examination of Oral Mucosal Disease. Before receiving DAA treatment and 24 weeks after SVR (SVR24), the oral mucosae were examined using a headlamp (Welch Allyn Ltd.). The diagnosis of OLP was made clinically and/or histopathologically. Information regarding the daily frequency of tooth brushing, smoking habits, and alcohol consumption was collected from the patients.
2.3. Saliva Sample Collection. A total of $1 \mathrm{~mL}$ of saliva was collected from the patients following chewing a nonflavored gum for $5 \mathrm{~min}$. All samples were immediately sent to the Health Examination Laboratory (BML, Inc., Tokyo, Japan) for bacterial testing [27]. Saliva was collected twice from each patient, before receiving DAA treatment and after SVR24. The subjects did not change their lifestyle before or after DAA treatment, did not receive active treatment for periodontal disease, and did not receive antibiotic treatment.

2.4. Identification of Periodontitis Bacteria and Detection of $P$. gingivalis fimA Genotypes. The total number of bacteria in saliva and the counts of six types of periodontal pathogens (Aggregatibacter actinomycetemcomitans; Prevotella intermedia; P. gingivalis; T. forsythia; T. denticola; and Fusobacterium nucleatum) were quantified using the modified polymerase chain reaction (PCR) Invader assay, as described previously [28]. The ratio of the number of periodontal disease bacteria to the total number of bacteria was examined (e.g., salivary $P$. gingivalis ratio (ratio: $P$. gingivalis counts/total bacteria counts)). Then, those with a high percentage of periodontal disease bacteria were judged to be at risk [26]. Based on the ratio of each periodontal pathogen to the total bacterial count, the following criteria were used to assess the risk: (i) A. actinomycetemcomitans; no risk: $<0.005 \%$ and risk: $\geq 0.005 \%$; (ii) $P$. intermedia; no risk: $<0.09 \%$ and risk: $\geq 0.09 \%$; (iii) P. gingivalis; no risk: $<0.09 \%$ and risk: $\geq 0.09 \%$; (iv) T. forsythia; no risk: $<0.09 \%$ and risk: $\geq 0.09 \%$; (v) T. denticola; no risk: $<0.09 \%$ and risk: $\geq 0.09 \%$; and (vi) F. nucleatum; no risk: $<5 \%$ and risk: $\geq 5 \%$. The red-complex bacteria were divided into two categories based on the aforementioned risk criteria: cases in which the percentage of at least one of the three red-complex bacteria increased (with risk) and cases in which there was no risk at all (without risk). P. gingivalis-specific fimA genotypes, ranging from types I to $\mathrm{V}$, were detected in all patients. The periodontitis bacteria were identified in each patient, before receiving DAA treatment and after SVR24.

2.5. Serological Assays. All subjects were assessed for white blood cell (WBC) counts, red blood cell (RBC) counts, hemoglobin $(\mathrm{Hb})$, platelet $(\mathrm{Plt})$ counts, aspartate aminotransferase (AST), alanine aminotransferase (ALT), lactate dehydrogenase (LDH), alkaline phosphatase (ALP), total protein (T. pro), albumin (Alb), total bilirubin (T. Bil), fasting blood glucose, HbAlc levels, total cholesterol (T. cho), and alpha-fetoprotein (AFP). All the biochemical parameters were measured by standard clinical methods using venous blood samples taken the morning after a $12 \mathrm{~h}$ overnight fast.

2.6. Evaluation of Liver Diseases. Anti-HCV was measured using a chemiluminescent enzyme immunoassay kit (Lumipulse II HCV; Fujirebio). HCV RNA in serum was analyzed using a standardized automated quantitative PCR (COBAS AMPLICOR HCV MONITOR v2.0 Test; COBAS ${ }^{\circledast}$ AmpliPrep/COBAS ${ }^{\circledast}$ Taq-Man ${ }^{\circledast}$ HCV Test; Roche Molecular Diagnostics) as reported previously [29]. Similarly, HCV 
TABLE 1: Characteristics of the subjects $(n=4)$.

\begin{tabular}{|c|c|c|c|c|}
\hline No. & 1 & 2 & 3 & 4 \\
\hline Sex & Female & Male & Female & Male \\
\hline Age & 76 & 72 & 65 & 77 \\
\hline Liver diseases & $\mathrm{CH}-\mathrm{C}$, after $\mathrm{HCC}$ & $\mathrm{CH}-\mathrm{C}$, after $\mathrm{HCC}$ & $\mathrm{CH}-\mathrm{C}$ & LC-C, after HCC \\
\hline $\begin{array}{l}\text { HCV genotype/level of HCV } \\
\text { RNA }\end{array}$ & 1b/high & 1b/high & 2a/low & 1b/high \\
\hline $\begin{array}{l}\text { Past history of IFN therapy } \\
\text { (yes/no) }\end{array}$ & Yes & No & Yes & No \\
\hline DAA type & DCV/ASV & DCV/ASV & SOF/RBV & $\mathrm{DCV} / \mathrm{ASV}$ \\
\hline HBsAg & Negative & Negative & Negative & Negative \\
\hline $\begin{array}{l}\text { Types of OLP before DAA } \\
\text { treatment }\end{array}$ & Erosive & Erosive & Reticular & Erosive \\
\hline $\begin{array}{l}\text { Sites of OLP before DAA } \\
\text { treatment }\end{array}$ & $\begin{array}{l}\text { Bilateral buccal } \\
\text { mucosa }\end{array}$ & $\begin{array}{l}\text { Bilateral buccal } \\
\text { mucosa and lower lip }\end{array}$ & $\begin{array}{c}\text { Bilateral buccal mucosa, } \\
\text { tongue, and sublingual } \\
\text { mucosa }\end{array}$ & Lower lip \\
\hline $\begin{array}{l}\text { Systemic disease other than } \\
\text { liver disease }\end{array}$ & $\begin{array}{l}\text { OLP, hypertension, } \\
\text { and glaucoma }\end{array}$ & $\begin{array}{l}\text { OLP and diabetes } \\
\text { mellitus }\end{array}$ & OLP & $\begin{array}{l}\text { OLP, diabetes mellitus, } \\
\text { hypertension, and renal } \\
\text { failure }\end{array}$ \\
\hline $\begin{array}{l}\text { Outcome of OLP after } \\
\text { SVR24 }\end{array}$ & Disappearance & Disappearance & Improvement & Disappearance \\
\hline Smoking history (yes/no) & No & Yes & No & Yes \\
\hline Alcohol intake (yes/no) & No & Yes & No & No \\
\hline $\begin{array}{l}\text { BMI }\left(\mathrm{kg} / \mathrm{m}^{2}\right) \text { before DAA } \\
\text { treatment }\end{array}$ & 22.7 & 24.9 & 25.1 & 20.1 \\
\hline $\begin{array}{l}\text { A habit of brushing teeth } \\
\text { after meals (more than twice) } \\
\text { (yes/no) }\end{array}$ & Yes & Yes & Yes & Yes \\
\hline
\end{tabular}

Patient no. 4 was undergoing dialysis treatment. HCV, hepatitis C virus; IFN, interferon; CH-C, chronic hepatitis C; LC, liver cirrhosis; HCC, hepatocellular carcinoma; DAA, direct-acting antiviral agent; DCV, daclatasvir; ASV, asunaprevir; SOF, sofosbuvir; RBV, ribavirin; HBsAg, hepatitis B surface antigen; OLP, oral lichen planus; SVR, sustained virological response; and BMI, body mass index.

genotypes were determined by PCR, as reported previously [30]. Ultrasonography was performed on all patients to examine the shape of the liver and to identify the lesions in the organ. Computed tomography was performed on all patients.

2.7. Ethics Approval. The study was conducted according to the guidelines of the Declaration of Helsinki and approved by the Ethical Committee of Saga University (reference no. 2015-02-16 and 29-71) and the Ethics Committee of Kurume University (reference no. 12240). Written informed consent for participation in the study was obtained from each patient.

\section{Results}

3.1. Periodontitis Bacteria and Detection of P. gingivalis fimA Genotypes. Table 2 shows the changes in periodontal disease bacteria from before DAA treatment to after SVR. After SVR, the total number of periodontal bacteria and the numbers of $P$. gingivalis, $T$. forsythia, $T$. denticola, and F. nucleatum decreased. After SVR, the number of A. actinomycetemcomitans remained unchanged and the number of $P$. intermedia increased. Two patients (50\%) were at risk for at least one of the three types of red-complex bacteria before DAA treatment, but none $(0 \%)$ after SVR (Table 2). The type of $P$. gingivalis fimA did not change with
DAA treatment: one patient had type II, one had type III, and the remaining two were undetectable.

3.2. OLP. Four patients did not receive any specific drug therapy for OLP during DAA treatment but, after SVR24 with DAA treatment, OLP lesions disappeared in three of the four OLP patients and improved in the other (Table 1).

3.3. Liver Diseases. All subjects achieved SVR at the end of treatment. A comparison of the biochemical data at baseline and SVR24 is shown in Table 2. At SVR24, the serum AST, ALT, LDH, ALP, and AFP levels decreased to normal and the Alb levels increased. The BMI did not change before and after treatment. No clinical adverse events were observed in the patients.

\section{Discussion}

DAA treatment of hepatitis $\mathrm{C}$ is a remarkable development. The elimination of HCV by DAA treatment has long-term benefits [31] and leads to improved outcomes at all stages of liver disease [32]. HCV elimination with DAA treatment shows the following benefits: reduction of liver fibrosis and portal hypertension [33], reduced incidence of HCC [34], reduced liver-related mortality [35], reduced incidence of diabetes [36], reduced incidence of cardiovascular disease [37], reduced risk of developing mixed cryoglobulinemia, 
TABLE 2: Comparison of the biochemical and periodontitis bacteria data at baseline and SVR24.

\begin{tabular}{|c|c|c|}
\hline Category [normal range] & Baseline & SVR24 \\
\hline BMI $\left(\mathrm{kg} / \mathrm{m}^{2}\right)($ mean $\pm \mathrm{SD})[18.5-25.0]$ & $23.2 \pm 2.4$ & $22.9 \pm 2.5$ \\
\hline Obesity $(\mathrm{BMI} \geqq 25)(n, \%)$ & $1(25 \%)$ & $1(25 \%)$ \\
\hline AST $(\mathrm{U} / \mathrm{L})($ mean $\pm \mathrm{SD})[13-30]$ & $43.5 \pm 19.1$ & $24.0 \pm 11.8$ \\
\hline $\operatorname{ALT}(\mathrm{U} / \mathrm{L})($ mean $\pm \mathrm{SD})[7-30]$ & $39.8 \pm 20.9$ & $19.0 \pm 11.2$ \\
\hline $\mathrm{LDH}(\mathrm{U} / \mathrm{L})($ mean $\pm \mathrm{SD})[118-229]$ & $234.0 \pm 89.7$ & $218.7 \pm 37.5$ \\
\hline $\operatorname{ALP}(\mathrm{U} / \mathrm{L})($ mean $\pm \mathrm{SD})[106-322]$ & $385.0 \pm 272.3$ & $241.5 \pm 112.6$ \\
\hline T. pro $(\mathrm{g} / \mathrm{dL})($ mean $\pm \mathrm{SD})[6.60-8.10]$ & $7.57 \pm 0.68$ & $7.27 \pm 0.59$ \\
\hline Alb $(\mathrm{g} / \mathrm{dL})($ mean $\pm \mathrm{SD})[4.10-5.10]$ & $3.91 \pm 0.38$ & $4.01 \pm 0.40$ \\
\hline T. Bil $(\mathrm{mg} / \mathrm{dL})(\mathrm{mean} \pm \mathrm{SD})[0.40-1.20]$ & $0.74 \pm 0.33$ & $0.56 \pm 0.10$ \\
\hline Fasting glucose $(\mathrm{mg} / \mathrm{dL})($ mean $\pm \mathrm{SD})[73-109]$ & $90.0 \pm 12.2$ & $100.3 \pm 20.6$ \\
\hline HbAlc $(\%)($ mean \pm SD) $[4.9-6.0]$ & $5.70 \pm 0.26$ & $5.80 \pm 0.44$ \\
\hline T.cho $(\mathrm{mg} / \mathrm{dL})($ mean $\pm \mathrm{SD})[142-219]$ & $153.3 \pm 20.7$ & $211.7 \pm 38.7$ \\
\hline RBC $\left(10^{4} / \mu \mathrm{L}\right)($ mean $\pm \mathrm{SD})($ Male:435-555 and female: $386-492)$ & $400.0 \pm 63.0$ & $446.8 \pm 46.5$ \\
\hline $\mathrm{Hb}(\mathrm{g} / \mathrm{dL})($ mean $\pm \mathrm{SD})($ male: $13.7-16.8$ and female: $11.6-14.8)$ & $12.7 \pm 2.8$ & $10.4 \pm 3.2$ \\
\hline WBC $\left(10^{2} / \mu \mathrm{L}\right)($ mean \pm SD) $[33-86]$ & $41.4 \pm 5.6$ & $58.1 \pm 6.5$ \\
\hline Plt $\left(10^{4} / \mu \mathrm{L}\right)($ mean $\pm \mathrm{SD})[15.8-34.8]$ & $12.0 \pm 6.9$ & $10.4 \pm 3.2$ \\
\hline $\operatorname{AFP}(\mathrm{ng} / \mathrm{mL})($ mean $\pm \mathrm{SD})[0.0-7.0]$ & $64.2 \pm 122.3$ & $4.8 \pm 4.7$ \\
\hline Total number of bacteria in saliva $($ copies $/ 10 \mu \mathrm{l})($ mean \pm SD $)$ & $11.622,500 \pm 7.786,957$ & $5.975,000 \pm 3.765,966$ \\
\hline Number of $A$. actinomycetemcomitans in saliva (copies/10 $\mu \mathrm{l})($ mean $\pm \mathrm{SD})$ & $10 \pm 0$ & $10 \pm 0$ \\
\hline Number of $P$. intermedia in saliva $($ copies $/ 10 \mu \mathrm{l})($ mean $\pm S D)$ & $8.596 \pm 11.263$ & $9.513 \pm 12.872$ \\
\hline Number of $P$. gingivalis in saliva $($ copies $/ 10 \mu \mathrm{l})($ mean \pm SD) & $2.440 \pm 2.791$ & $1.445 \pm 2.705$ \\
\hline Number of $T$. forsythia in saliva (copies $/ 10 \mu \mathrm{l})($ mean $\pm \mathrm{SD})$ & $7.570 \pm 9.176$ & $1.530 \pm 2.023$ \\
\hline Number of $T$. denticola in saliva (copies/10 $\mu \mathrm{l})($ mean $\pm \mathrm{SD})$ & $1.470 \pm 1.580$ & $770 \pm 1.355$ \\
\hline Number of $F$. nucleatum in saliva (copies $/ 10 \mu \mathrm{l})($ mean \pm SD) & $591.275 \pm 758.110$ & $191.750 \pm 326.387$ \\
\hline Risk of $A$. actinomycetemcomitans (ratio of the total bacterial count $>0.006 \%$ ) (yes, \%) & $0(0 \%)$ & $0(0 \%)$ \\
\hline Risk of $P$. intermedia (ratio of the total bacterial count $>0.1 \%$ ) (yes, \%) & $1(25 \%)$ & $2(50 \%)$ \\
\hline Risk of $P$. gingivalis (ratio of the total bacterial count $>0.1 \%$ ) (yes, \%) & $0(0 \%)$ & $0(0 \%)$ \\
\hline Risk of T. forsythia (ratio of the total bacterial count $>0.1 \%$ ) (yes, \%) & $2(50 \%)$ & $0(0 \%)$ \\
\hline Risk of T. denticola (ratio of the total bacterial count $>0.1 \%)(n, \%)$ & $1(25 \%)$ & $0(0 \%)$ \\
\hline Risk of F. nucleatum (ratio of the total bacterial count $>5 \%$ ) (yes, \%) & $1(25 \%)$ & $1(25 \%)$ \\
\hline Risk for at least one of the 3 types of red complex bacteria (yes, \%) & $2(50 \%)$ & $0(0 \%)$ \\
\hline \multicolumn{3}{|l|}{ P. gingivalis fimA } \\
\hline - Genotype II $(n, \%)$ & $1(25 \%)$ & $1(25 \%)$ \\
\hline - Genotype III ( $n, \%)$ & $1(25 \%)$ & $1(25 \%)$ \\
\hline - Below detection sensitivity limits $(n, \%)$ & $2(50 \%)$ & $2(50 \%)$ \\
\hline
\end{tabular}

SD, standard deviation; SVR, sustained virological response; BMI, body mass index; AST, aspartate aminotransferase; ALT, alanine aminotransferase; LDH, lactate dehydrogenase; ALP, alkaline phosphatase; T. pro, total protein; Alb, albumin; T. Bil, total bilirubin; T. cho, total cholesterol; RBC, red blood cell; Hb, hemoglobin; WBC, white blood cell; Plt, platelet; and AFP, alpha-fetoprotein.

glomerulonephritis, and lichen planus [38], improved patient quality of life [39], and reduced all-cause mortality [35].

In this study, we investigated the effects of DAA on periodontal disease and OLP. Not only did OLP lesions disappear or improve when HCV was eliminated but also the number of periodontal bacteria and the content of redcomplex periodontal bacteria decreased. This is the first report of a decrease in the number of periodontal disease bacteria following HCV elimination. The conventional IFN treatment of OLP patients with HCV infection has the disadvantage that OLP often worsens during treatment and the treatment cannot be completed [40-42]. However, DAA therapy has fewer side effects than IFN therapy and results in an SVR rate of over 90\% [43-45]. We reported previously that DAA treatment of HCV-infected OLP does not worsen OLP lesions during treatment and that OLP improves or is cured after HCV elimination $[16,17,19]$. Su et al. reported that elimination of HCV also reduced the incidence of oral cancer; in a nationwide population study, HCV-infected individuals had a significantly increased risk of both OLP and oral cancer compared to noninfected individuals and antiviral therapy with pegylated IFN (PegIFN) and RBV significantly reduced the risk of HCV-related oral cancer [46]. We reported previously a high prevalence of $\mathrm{HCV}$ infection in oral cancer [47] and multiple primary squamous cell carcinoma of the head and neck [48, 49]. HCV-positive OLP lesions are considered to be at high risk of malignant transformation [50]. A genome-wide association analysis (GWAS) analysis of Japanese HCV-infected patients showed that HLA-DR/DQ genes were significantly associated with the development of HCV-related OLP [51], which supported previous reports [52]. Furthermore, we identified rs884000 of neuropilin-2 (NRP2) and rs538399 of insulin-like growth binding protein factor 4 (IGFBP4) as novel associations, indicating that these two SNPs may be involved in the malignant transformation of HCVinfected OLP [51]. Further studies are needed to clarify the link between $\mathrm{HCV}$ and oral carcinogenesis, but there is no doubt that HCV elimination is beneficial. 
$\mathrm{HCV}$ infection is known to stimulate the immune system, causing cytokine production and chronic inflammation [53]. HCV is involved in vascular inflammation through the activation of tumor necrosis factor alpha (TNF $\alpha$ ), causing the activation and adhesion of inflammatory cells in the blood vessels [54]. HCV core proteins cause immune activation, inflammation, and tumorigenesis through the signal transducer and activator of the transcription 3 (STAT 3) pathway [55]. On the other hand, lipopolysaccharide (LPS), a component of the cell wall of periodontopathogenic bacteria, invades gingival tissues, activates neutrophils and macrophages, and produces various proinflammatory factors such as interleukin- (IL-) $1 \beta$, IL-6, TNF $\alpha$, and matrix metalloproteinases (MMPs) [56]. Gingipain, a cysteine protease produced by $P$. gingivalis, a major periodontopathogenic bacterium, activates MMP precursors [57], and $P$. gingivalis fimbriae act on macrophages and gingival fibroblasts to induce the production of inflammatory cytokines [58]. Azatyan et al. reported that oral fluid cytokine levels were significantly higher in patients with $\mathrm{HCV}, \mathrm{HBV}$, and HIV than in controls [59].

$\mathrm{HCV}$ infection is associated with a higher incidence of dental caries and periodontal disease than in healthy individuals, a trend that is likely to become more pronounced as liver fibrosis progresses. Coates et al. pointed out a trend of poor periodontal disease in hepatitis $\mathrm{C}$ patients, although this was not statistically significant [60]. We reported previously that the following five factors were associated with periodontal disease in 351 patients with liver disease attributable to HBV or HCV: Plt count $<80,000$, daily tooth brushing, current IFN treatment, age $>65$ years, and obesity [25]. The adjusted odds ratios for these factors were 5.80, $3.46,2.87,2.50$, and 2.33 , respectively, and were statistically significant. The periodontal pathogens' composition is generally influenced by aging [61]. Toljić et al. reported that HIV infection significantly increases the bacterial load in the oral cavity and alters the pattern of microflora composition during the aging process [61]. We also reported that the prevalence of fimA genotype II was higher in cirrhotic patients with advanced fibrosis than in chronic hepatitis [25] and that the red complex was associated with cirrhotic patients [26].

The reasons for the decreased risk of the red complex after HCV elimination in this study may be the reduction of inflammatory cytokines in the oral cavity, improvement of insulin resistance, improvement of OLP lesions, and involvement of the gut microbiota. Recently, it has been reported that disruption of the gut microbiota (so-called dysbiosis) is associated with liver diseases, such as nonalcoholic fatty liver (NAFL) and NASH [62], liver cirrhosis [63], primary biliary cholangitis [64], and HCV-related liver disease [65-67]. It has been reported that gut microbiota dysbiosis in $\mathrm{HCV}$-infected patients already appears at the stage of PNALT (persistently normal serum alanine aminotransferase) and is associated with the severity of the clinical stages (i.e., PNALT, chronic hepatitis, liver cirrhosis, and HCC) [65]. In a study investigating the effects of antiviral drugs on the gut microbiota of HCV patients, Ponziani et al. reported significant improvement in gut microbiota dysbiosis after successful DAA treatment of $\mathrm{HCV}$-infected patients [68]. In our preliminarily study, all four patients had a reduction in periodontal bacteria after SVR. Whether HCV elimination affects both gut bacteria and oral periodontal bacteria is a question that needs further investigation.

Among the subjects of this study, case No. 4 (77 years old, male), a cirrhotic patient with HCV infection who had been treated for HCC (see Table 1), was recommended by an oral surgeon to a hepatologist for DAA treatment. He had never received any explanation from his family doctor about antiviral treatment with DAA therapy. So, the oral surgeon explained to him that DAA treatment is the standard treatment for hepatitis $\mathrm{C}$ in Japan and that HCV elimination reduces the recurrence of HCC and may also cure OLP and then referred him to a hepatologist. The patient was treated with DAA which resulted in SVR and disappearance of the OLP lesions. It has been four and a half years since SVR, and the patient's HCC has not recurred.

In recent years, the number of $\mathrm{HCV}$-infected people has been decreasing due to the development of DAA treatment, but the existence of $\mathrm{HCV}$-infected individuals who have not yet been diagnosed and $\mathrm{HCV}$ patients who have not received appropriate treatment remains a challenge. It is estimated that about 3 million individuals in Japan are infected with HBV and HCV and about 800,000 are unaware of their infection [5]. Of the HCV-infected individuals in Japan, it is estimated that about 470,000 visit medical institutions, about 300,000 are unaware that they are infected, and about 250,000-750,000 are aware that they are infected with HCV but do not receive treatment [69]. We reported that it is possible for dentists to pick out $\mathrm{HCV}$-infected patients from among those who visit dental clinics for the treatment of dental and oral diseases $[17,18,70,71]$. The detection of potential $\mathrm{HCV}$-infected patients by dentists as gatekeepers can contribute to the reduction of liver carcinogenesis [72].

The present study has some limitations. First, the sample was very small. Second, the study was not conducted in a control group setting. Future studies need to be large casecontrol studies to clarify the effects of periodontal bacteria.

\section{Conclusions}

In this pilot study, HCV elimination was found to not only improve OLP but also reduce the number of periodontal bacteria. It is important to emphasize that further studies are needed due to the small number of cases. HCV elimination will bring a new perspective on the importance of oral management since HCV infection may be a risk for worsening periodontal disease.

\section{Abbreviations}

HCV: Hepatitis $C$ virus

HBV: Hepatitis B virus

HCC: Hepatocellular carcinoma

OLP: Oral lichen planus

IFN: Interferon

DAA: Direct-acting antiviral agent 
SVR: Sustained virological response

BMI: Body mass index

RBC: $\quad$ Red blood cell

WBC: White blood cell

Plt: Platelet

Hb: Hemoglobin

ALT: $\quad$ Serum alanine aminotransferase

AST: Aspartate aminotransferase

LDH: Lactate dehydrogenase

ALP: Alkaline phosphatase

T. Bil: Total bilirubin

T. cho: Total cholesterol

T. pro: Total protein

Alb: Albumin

AFP: Alpha-fetoprotein.

\section{Data Availability}

All the datasets generated and analyzed in the present study are included in this published article.

\section{Conflicts of Interest}

The authors declare no conflicts of interest.

\section{Authors' Contributions}

YN designed the study, collected data from participants, and wrote the manuscript. MT interpreted data and added intellectual revision. Both the authors have read and approved the final version.

\section{Acknowledgments}

This study was supported in part by the Japan Society for the Promotion of Science (JSPS) KAKENHI, Grant nos. JP17K12012, and JP21K10263. The authors would like to thank Dr. Kazunori Noguchi (Omuta City Hospital) and Dr. Ryoko Kuromatsu (Kurume University) for their support during data collection and all the comedical Tsuji Dental and Oral Surgery Clinic staff for assistance.

\section{References}

[1] GBD 2013 Mortality and Causes of Death Collaborators, "Global regional, and national age-sex specific all-cause and cause-specific mortality for 240 causes of death, 1990-2013: a systematic analysis for the Global Burden of Disease Study 2013," The Lancet, vol. 385, pp. 117-171, 2015.

[2] Polaris Observatory HCV Collaborators, "Global prevalence and genotype distribution of hepatitis $\mathrm{C}$ virus infection in 2015: a modelling study," The Lancet Gastroenterology \& Hepatology, vol. 2, no. 3, pp. 161-176, 2017.

[3] T. Umemura, T. Ichijo, K. Yoshizawa, E. Tanaka, and K. Kiyosawa, "Epidemiology of hepatocellular carcinoma in Japan," Journal of Gastroenterology, vol. 44, no. Suppl 19, pp. 102-107, 2009.

[4] Y. Asahina, K. Tsuchiya, N. Tamaki et al., "Effect of aging on risk for hepatocellular carcinoma in chronic hepatitis $\mathrm{C}$ virus infection," Hepatology, vol. 52, no. 2, pp. 518-527, 2010.
[5] J. Tanaka, T. Koyama, M. Mizui et al., "Total numbers of undiagnosed carriers of hepatitis $\mathrm{C}$ and $\mathrm{B}$ viruses in Japan estimated by age- and area-specific prevalence on the national scale," Intervirology, vol. 54, no. 4, pp. 185-195, 2011.

[6] G. S. Cooke, I. Andrieux-Meyer, T. L. Applegate et al., "Accelerating the elimination of viral hepatitis: a lancet gastroenterology \& hepatology commission," The Lancet Gastroenterology \& Hepatology, vol. 4, no. 2, pp. 135-184, 2019.

[7] World Health Organization, Global Hepatitis Report, WHO, Geneva, Switzerland, 2017.

[8] World Health Organization, Progress Report on Access to Hepatitis C Treatment: Focus on Overcoming Barriers in Lowand Middle-Income Countries, World Health Organization, Geneva, Switzerland, 2018.

[9] Z. Younossi, H. Park, L. Henry, A. Adeyemi, and M. Stepanova, "Extrahepatic manifestations of hepatitis C: a meta-analysis of prevalence, quality of life, and economic burden," Gastroenterology, vol. 150, no. 7, pp. 1599-1608, 2016.

[10] Y. Nagao, M. Sata, K. Tanikawa, K. Itoh, and T. Kameyama, "Lichen planus and hepatitis $\mathrm{C}$ virus in the northern Kyushu region of Japan," European Journal of Clinical Investigation, vol. 25, no. 12, pp. 910-914, 1995.

[11] G. Lodi, C. Scully, M. Carrozzo, M. Griffiths, P. B. Sugerman, and K. Thongprasom, "Current controversies in oral lichen planus: report of an international consensus meeting. Part 1. Viral infections and etiopathogenesis," Oral Surgery, Oral Medicine, Oral Pathology, Oral Radiology \& Endodontics, vol. 100, no. 1, pp. 40-51, 2005.

[12] G. Chamani, M. Rad, M. R. Zarei, S. Lotfi, M. Sadeghi, and Z. Ahmadi, "Efficacy of tacrolimus and clobetasol in the treatment of oral lichen planus: a systematic review and metaanalysis," International Journal of Dermatology, vol. 54, no. 9, pp. 996-1004, 2015.

[13] P. G. Arduino, M. Carbone, F. Della Ferrera et al., "Pimecrolimus vs. tacrolimus for the topical treatment of unresponsive oral erosive lichen planus: a 8 week randomized double-blind controlled study," Journal of the European Academy of Dermatology and Venereology, vol. 28, no. 4, pp. 475-482, 2014.

[14] Y. Nagao, M. Sata, H. Suzuki, K. Tanikawa, K. Itoh, and T. Kameyama, "Effectiveness of glycyrrhizin for oral lichen planus in patients with chronic HCV infection," Journal of Gastroenterology, vol. 31, no. 5, pp. 691-695, 1996.

[15] Y. Nagao, M. Sata, H. Suzuki, T. Kameyama, and T. Ueno, "Histological improvement of oral lichen planus in patients with chronic hepatitis C treated with interferon," Gastroenterology, vol. 117, no. 1, pp. 283-284, 1999.

[16] Y. Nagao, K. Kimura, Y. Kawahigashi, and M. Sata, "Successful treatment of hepatitis $\mathrm{C}$ virus-associated oral lichen planus by interferon-free therapy with direct-acting antivirals," Clinical and Translational Gastroenterology, vol. 7, no. 7, Article ID e179, 2016.

[17] K. Misaka, T. Kishimoto, Y. Kawahigashi, M. Sata, and Y. Nagao, "Use of direct-acting antivirals for the treatment of hepatitis C virus-associated oral lichen planus: a case report," Case Reports in Gastroenterology, vol. 10, no. 3, pp. 617-622, 2016.

[18] Y. Nagao and M. Tsuji, "The discovery through dentistry of potentially HCV-Infected Japanese patients and intervention with treatment," Advanced Research in Gastroenterology and Hepatology, vol. 7, pp. 38-44, 2017.

[19] K. Harada, D. Nakashima, Y. Nagao, I. Hidaka, I. Sakaida, and K. Mishima, "Treatment of refractory oral lichen planus using 
direct antiviral agents in a patient with chronic hepatitis C: a case report," Oral Science International, vol. 17, no. 3, pp. 213-217, 2020.

[20] L. I. Backus, D. B. Boothroyd, B. R. Phillips, P. Belperio, J. Halloran, and L. A. Mole, "A sustained virologic response reduces risk of all-cause mortality in patients with hepatitis C," Clinical Gastroenterology and Hepatology, vol. 9, no. 6, pp. 509-516, Article ID e501, 2011.

[21] N. A. Terrault and T. I. Hassanein, "Management of the patient with SVR," Journal of Hepatology, vol. 65, no. 1, pp. S120-s129, 2016.

[22] A. Falcao and P. Bullon, "A review of the influence of periodontal treatment in systemic diseases," Periodontol 2000, vol. 79, pp. 117-128, 2019.

[23] M. Yoneda, S. Naka, K. Nakano et al., "Involvement of a periodontal pathogen, Porphyromonas gingivalis on the pathogenesis of non-alcoholic fatty liver disease," $B M C$ Gastroenterology, vol. 12, no. 16, p. 16, 2012.

[24] G. Isola, A. Polizzi, A. Alibrandi, R. C. Williams, and A. Lo Giudice, "Analysis of galectin-3 levels as a source of coronary heart disease risk during periodontitis," Journal of Periodontal Research, vol. 56, no. 3, pp. 597-605, 2021.

[25] Y. Nagao, Y. Kawahigashi, and M. Sata, "Association of periodontal diseases and liver fibrosis in patients with HCV and/or HBV infection," Hepatitis Monthly, vol. 14, Article ID e23264, 2014.

[26] Y. Nagao and T. Tanigawa, "Red complex periodontal pathogens are risk factors for liver cirrhosis," Biomedical Reports, vol. 11, pp. 199-206, 2019.

[27] A. Tada, H. Takeuchi, H. Shimizu et al., "Quantification of periodontopathic bacteria in saliva using the invader assay," Japanese Journal of Infectious Diseases, vol. 65, no. 5, pp. 415-423, 2012.

[28] K. Tadokoro, T. Yamaguchi, K. Kawamura et al., "Rapid quantification of periodontitis-related bacteria using a novel modification of Invader PLUS technologies," Microbiological Research, vol. 165, no. 1, pp. 43-49, 2010.

[29] D. Sizmann, C. Boeck, J. Boelter et al., "Fully automated quantification of hepatitis $\mathrm{C}$ virus (HCV) RNA in human plasma and human serum by the COBAS AmpliPrep/COBAS TaqMan system," Journal of Clinical Virology, vol. 38, no. 4, pp. 326-333, 2007.

[30] G. Dusheiko, H. Schmilovitz-Weiss, D. Brown et al., "Hepatitis $\mathrm{C}$ virus genotypes: an investigation of type-specific differences in geographic origin and disease," Hepatology, vol. 19, no. 1, pp. 13-18, 1994.

[31] G. N. Ioannou and J. J. Feld, "What are the benefits of a sustained virologic response to direct-acting antiviral therapy for hepatitis C virus infection?" Gastroenterology, vol. 156, no. 2, pp. 446-460, Article ID e442, 2019.

[32] V. Calvaruso and A. Craxì, "Hepatic benefits of HCV cure," Journal of Hepatology, vol. 73, no. 6, pp. 1548-1556, 2020.

[33] V. Knop, D. Hoppe, T. Welzel et al., "Regression of fibrosis and portal hypertension in $\mathrm{HCV}$-associated cirrhosis and sustained virologic response after interferon-free antiviral therapy," Journal of Viral Hepatitis, vol. 23, no. 12, pp. 994-1002, 2016.

[34] G. N. Ioannou, P. K. Green, and K. Berry, "HCV eradication induced by direct-acting antiviral agents reduces the risk of hepatocellular carcinoma," Journal of Hepatology, vol. 17, pp. S0168-8278, Article ID 32273-0, 2017.

[35] L. I. Backus, P. S. Belperio, T. A. Shahoumian, and L. A. Mole, "Impact of sustained virologic response with direct-acting antiviral treatment on mortality in patients with advanced liver disease," Hepatology, vol. 69, no. 2, pp. 487-497, 2019.
[36] J. Hum, J. H. Jou, P. K. Green et al., "Improvement in glycemic control of type 2 diabetes after successful treatment of hepatitis C virus," Diabetes Care, vol. 40, no. 9, pp. 1173-1180, 2017.

[37] S. Petta, L. E. Adinolfi, A. L. Fracanzani et al., "Hepatitis C virus eradication by direct-acting antiviral agents improves carotid atherosclerosis in patients with severe liver fibrosis," Journal of Hepatology, vol. 69, no. 1, pp. 18-24, 2018.

[38] H. B. El-Serag, I. C. Christie, A. Puenpatom, D. Castillo, F. Kanwal, and J. R. Kramer, "The effects of sustained virological response to direct-acting anti-viral therapy on the risk of extrahepatic manifestations of hepatitis C infection," Alimentary Pharmacology \& Therapeutics, vol. 49, no. 11, pp. 1442-1447, 2019.

[39] Z. M. Younossi, M. Stepanova, N. Afdhal et al., "Improvement of health-related quality of life and work productivity in chronic hepatitis $\mathrm{C}$ patients with early and advanced fibrosis treated with ledipasvir and sofosbuvir," Journal of Hepatology, vol. 63, no. 2, pp. 337-345, 2015.

[40] Y. Nagao, M. Sata, T. Ide et al., "Development and exacerbation of oral lichen planus during and after interferon therapy for hepatitis C," European Journal of Clinical Investigation, vol. 26, no. 12, pp. 1171-1174, 1996.

[41] Y. Nagao, T. Kawaguchi, T. Ide, R. Kumashiro, and M. Sata, "Exacerbation of oral erosive lichen planus by combination of interferon and ribavirin therapy for chronic hepatitis C," International Journal of Molecular Medicine, vol. 15, pp. 237-241, 2005.

[42] S. d. M. C. Grossmann, R. Teixeira, M. C. F. de Aguiar, and M. A. V. do Carmo, "Exacerbation of oral lichen planus lesions during treatment of chronic hepatitis $\mathrm{C}$ with pegylated interferon and ribavirin," European Journal of Gastroenterology and Hepatology, vol. 20, no. 7, pp. 702-706, 2008.

[43] M. Manns, S. Pol, I. M. Jacobson et al., "All-oral daclatasvir plus asunaprevir for hepatitis $\mathrm{C}$ virus genotype $1 \mathrm{~b}$ : a multinational, phase 3, multicohort study," The Lancet, vol. 384, no. 9954, pp. 1597-1605, 2014.

[44] K. R. Reddy, M. Bourlière, M. Sulkowski et al., "Ledipasvir and sofosbuvir in patients with genotype 1 hepatitis $C$ virus infection and compensated cirrhosis: an integrated safety and efficacy analysis," Hepatology, vol. 62, no. 1, pp. 79-86, 2015.

[45] H. Kumada, Y. Suzuki, K. Ikeda et al., "Daclatasvir plus asunaprevir for chronic HCV genotype $1 \mathrm{~b}$ infection," Hepatology, vol. 59, no. 6, pp. 2083-2091, 2014.

[46] T. H. Su, T. C. Tseng, C. J. Liu et al., "Antiviral therapy against chronic hepatitis $\mathrm{C}$ is associated with a reduced risk of oral cancer," International Journal of Cancer, vol. 147, no. 3, pp. 901-908, 2020.

[47] Y. Nagao, M. Sata, K. Tanikawa, K. Itoh, and T. Kameyama, "High prevalence of hepatitis $\mathrm{C}$ virus antibody and RNA in patients with oral cancer," Journal of Oral Pathology \& Medicine, vol. 24, no. 8, pp. 354-360, 1995.

[48] M. Yoshida, Y. Nagao, M. Sata, J. Kusukawa, and T. Kameyama, "Multiple primary neoplasms and hepatitis C virus infection in oral cancer patients," Hepatology Research, vol. 9, no. 2-3, pp. 75-81, 1997.

[49] Y. Nagao and M. Sata, "High incidence of multiple primary carcinomas in HCV-infected patients with oral squamous cell carcinoma," Medical Science Monitor, vol. 15, no. 9, Article ID Cr453-459, 2009.

[50] M. González-Moles, I. Ruiz-Ávila, L. González-Ruiz, Á Ayén, J. A. Gil-Montoya, and P. Ramos-García, "Malignant transformation risk of oral lichen planus: a systematic review and 
comprehensive meta-analysis," Oral Oncology, vol. 96, pp. 121-130, 2019.

[51] Y. Nagao, N. Nishida, L. Toyo-Oka et al., "Genome-wide association study identifies risk variants for lichen planus in patients with hepatitis C virus infection," Clinical Gastroenterology and Hepatology, vol. 15, no. 6, pp. 937-944, Article ID e935, 2017.

[52] M. Carrozzo, F. Brancatello, E. Dametto et al., "Hepatitis C virus-associated oral lichen planus: is the geographical heterogeneity related to HLA-DR6?" Journal of Oral Pathology \& Medicine, vol. 34, no. 4, pp. 204-208, 2005.

[53] P. M. Jacobson Brown and M. G. Neuman, "Immunopathogenesis of hepatitis $\mathrm{C}$ viral infection: Th1/Th2 responses and the role of cytokines," Clinical Biochemistry, vol. 34, no. 3 , pp. 167-171, 2001.

[54] J. Pircher, T. Czermak, M. Merkle et al., "Hepatitis C virus induced endothelial inflammatory response depends on the functional expression of TNF $\alpha$ receptor subtype 2," PLoS One, vol. 9, no. 11, Article ID e113351, 2014.

[55] A. Basu, K. Meyer, K. K. Lai et al., "Microarray analyses and molecular profiling of Stat3 signaling pathway induced by hepatitis C virus core protein in human hepatocytes," $V i$ rology, vol. 349, no. 2, pp. 347-358, 2006.

[56] G. Atilla, T. Sorsa, H. Rönka, and G. Emingil, "Matrix metalloproteinases (MMP-8 and -9) and neutrophil elastase in gingival crevicular fluid of cyclosporin-treated patients," Journal of Periodontology, vol. 72, no. 3, pp. 354-360, 2001.

[57] R. Grayson, C. W. I. Douglas, J. Heath, A. Rawlinson, and G. S. Evans, "Activation of human matrix metalloproteinase 2 by gingival crevicular fluid andPorphyromonas gingivalis," Journal of Clinical Periodontology, vol. 30, no. 6, pp. 542-550, 2003.

[58] J. Sandros, C. Karlsson, D. F. Lappin, P. N. Madianos, D. F. Kinane, and P. N. Papapanou, "Cytokine responses of oral epithelial cells to Porphyromonas gingivalis infection," Journal of Dental Research, vol. 79, no. 10, pp. 1808-1814, 2000.

[59] V. Azatyan, L. Yessayan, M. Shmavonyan, G. MelikAndreasyan, A. Perikhanyan, and K. Porkshenyan, "Evaluation of IL-2, IL-10, IL-4 and $\gamma$-interferon levels in the oral fluids of patients with hepatitis C, B and HIV," Journal of Infection in Developing Countries, vol. 13, pp. 69s-74s, 2019.

[60] E. A. Coates, D. Brennan, R. M. Logan et al., "Hepatitis C infection and associated oral health problems," Australian Dental Journal, vol. 45, no. 2, pp. 108-114, 2000.

[61] B. Toljić, A. M. Trbovich, S. M. Petrović et al., "Ageing with HIV - a periodontal perspective," New Microbiologica, vol. 41, pp. 61-66, 2018.

[62] J. Boursier, O. Mueller, M. Barret et al., "The severity of nonalcoholic fatty liver disease is associated with gut dysbiosis and shift in the metabolic function of the gut microbiota," Hepatology, vol. 63, no. 3, pp. 764-775, 2016.

[63] N. Qin, F. Yang, A. Li et al., "Alterations of the human gut microbiome in liver cirrhosis," Nature, vol. 513, no. 7516, pp. 59-64, 2014.

[64] R. Tang, Y. Wei, Y. Li et al., "Gut microbial profile is altered in primary biliary cholangitis and partially restored after UDCA therapy," Gut, vol. 67, no. 3, pp. 534-541, 2018.

[65] T. Inoue, J. Nakayama, K. Moriya et al., "Gut dysbiosis associated with hepatitis C virus infection," Clinical Infectious Diseases, vol. 67, no. 6, pp. 869-877, 2018.

[66] R. Sehgal, O. Bedi, and N. Trehanpati, "Role of microbiota in pathogenesis and management of viral hepatitis," Frontiers in Cellular and Infection Microbiology, vol. 10, Article ID 341, 2020 .
[67] M. El-Mowafy, A. Elgaml, M. El-Mesery et al., "Changes of gut-microbiota-liver axis in hepatitis $\mathrm{C}$ virus infection," $\mathrm{Bi}$ ology, vol. 10, no. 1, p. 55, 2021.

[68] F. R. Ponziani, L. Putignani, F. Paroni Sterbini et al., "Influence of hepatitis $\mathrm{C}$ virus eradication with direct-acting antivirals on the gut microbiota in patients with cirrhosis," Alimentary Pharmacology \& Therapeutics, vol. 48, no. 11-12, pp. 1301-1311, 2018.

[69] J. Tanaka: Ministry of Health, Labor and Welfare 13th Council for Promotion of Measures against Hepatitis, 2015, (in Japanese) https://www.mhlw.go.jp/stf/shingi2/0000075691.html.

[70] Y. Nagao, T. Sasaki, T. Kuzuyama et al., "Promotion by dentists of treatment of undiagnosed and untreated HCVinfected patients," Advanced Research in Gastroenterology and Hepatology, vol. 9, pp. 86-90, 2018.

[71] Y. Nagao, S. Nishioka, and K. Koresawa, "Prevalence of viral liver disease and oral lichen planus in patients who visited dental clinics: a study by the Ehime Dental Association," OBM Hepatology and Gastroenterology, vol. 3, no. 2, p. 1, 2019.

[72] Y. Nagao, "The role of dentists in controlling hepatocellular carcinoma in Japan (Review)," Experimental and Therapeutic Medicine, vol. 21, no. 2, Article ID 113, 2021. 